\title{
Netrin-1 Attracts Axons through FAK-Dependent Mechanotransduction
}

\author{
Simon W. Moore, Xian Zhang, Christopher D. Lynch, and Michael P. Sheetz \\ Department of Biological Sciences, Columbia University, New York, New York 10027
}

The mechanism by which extracellular cues influence intracellular biochemical cascades that guide axons is important, yet poorly understood. Because of the mechanical nature of axon extension, we explored whether the physical interactions of growth cones with their guidance cues might be involved. In the context of mouse spinal commissural neuron axon attraction to netrin-1, we found that mechanical attachment of netrin-1 to the substrate was required for axon outgrowth, growth cone expansion, axon attraction and phosphorylation of focal adhesion kinase (FAK) and Crk-associated substrate (CAS). Myosin II activity was necessary for traction forces $>30 \mathrm{pN}$ on netrin-1. Interestingly, while these myosin II-dependent forces on netrin-1 substrates or beads were needed to increase the kinase activity and phosphorylation of FAK, they were not necessary for netrin-1 to increase CAS phosphorylation. When FAK kinase activity was inhibited, the growth cone's ability to recruit additional adhesions and to generate forces $>60 \mathrm{pN}$ on netrin-1 was disrupted. Together, these findings demonstrate an important role for mechanotransduction during chemoattraction to netrin-1 and that mechanical activation of FAK reinforces interactions with netrin-1 allowing greater forces to be exerted.

\section{Introduction}

Netrin-1 is a secreted protein that has been detected in all organisms with bilateral symmetry studied so far (Moore et al., 2007). It has known functions in axon guidance, tissue morphogenesis and cancer. In the context of axon guidance, netrin-1 is recognized by the transmembrane receptors Deleted in Colorectal Cancer (DCC), UNC5, and Down syndrome cell adhesion molecule (dsCAM) (Lai Wing Sun et al., 2011).

The extension of axons is primarily guided by patterned proteins in the extracellular space (Raper and Mason, 2010). In most cases, these guidance cues are physically tethered to a surface either because they span the membrane (e.g., ephrin-Bs and sema-1, -4, -5 and -6), are glycophosphatidylinositol (GPI)linked (e.g., ephrin-As and sema-7A) or, if secreted, they associate with extracellular matrix components (e.g., netrins, bone morphogenetic proteins, sema-3s and slits) (Hu, 2001; Manitt and Kennedy, 2002; De Wit et al., 2005; Rider, 2006). Netrin-1 can diffuse a few hundred micrometers from its source before adsorbing to surfaces. Specifically, when dorsal spinal cord explants were separated from netrin-1-expressing cells in a collagen gel, outgrowth was observed at distances of up to $\sim 250 \mu \mathrm{m}$ (Kennedy et al., 1994). Over a similar distance, a source of

\footnotetext{
Received Feb. 29, 2012; revised June 1, 2012; accepted June 29, 2012.

Author contributions: S.W.M., X.Z., and M.P.S. designed research; S.W.M. and C.D.L. performed research; S.W.M. and X.Z. contributed unpublished reagents/analytic tools; S.W.M. analyzed data; S.W.M. and M.P.S. wrote the paper.

This work was funded by the National Institutes of Health (NIH) Common Fund Nanomedicine program (PN2 EY016586) and NIH Grant 5R01GM03627. S.W.M. was supported by a postdoctoral fellowship from the Canadian Institute of Health Research and NIH Award 1K99NS075135. We thank Florencia Marcucci for help setting up electroporations and Sanaa Ansari for technical assistance.

Correspondence should be addressed to Dr. Simon W. Moore, Department of Biological Sciences, Columbia University, 1212 Amsterdam Avenue, New York, NY 10027. E-mail: sm3030@columbia.edu.

DOI:10.1523/JNEUROSCI.0999-12.2012

Copyright $\odot 2012$ the authors $\quad 0270-6474 / 12 / 3211574-12 \$ 15.00 / 0$
}

netrin-1 deflected the trajectory of spinal commissural axons within the neuroepithelium. However, it was also recognized that the majority of netrin-1 was not present in the soluble fraction, but rather in the membrane-bound fraction and could only be extracted with salt concentrations nearly 10 times higher than physiological $(1.2 \mathrm{M}$ ) (Serafini et al., 1994). As such there is a strong electrostatic interaction of netrin-1 with the extracellular environment. Further, it has been shown in different contexts that substrate attached netrin-1 is sufficient to reorient axons, including: dissociated hippocampal and commissural neuron axons on polylysine-coated surfaces (Mai et al., 2009; Moore et al., 2009) and for midline crossing of commissural neurons within the developing Drosophila melanogaster (Brankatschk and Dickson, 2006).

The growth cone both senses guidance cues and mechanically pulls the axon forward (Lamoureux et al., 1989; Davenport et al., 1993; Huber et al., 2003; Moore and Sheetz, 2011). The mechanical tethering of axon guidance cues raises the possibility that growth cones pull directly on the cues that guide them. Indeed, in the case of netrin-1, we have found that growth cones exert a direct pulling force of $>60 \mathrm{pN}$ during chemoattraction (Moore et al., 2009). To affect the trajectory of axons, guidance cues regulate intracellular biochemical signaling pathways (Bashaw and Klein, 2010). The mechanical relationship of the growth cone with its guidance cues could directly impact intracellular signaling events through a process known as mechanotransduction whereby mechanical forces alter the activity of physically linked intracellular proteins. A growing list of proteins behave as mechanotransducers, including: ion channels, intracellular kinases, extracellular matrix components and several adhesion-associated proteins (Moore et al., 2010; Hoffman et al., 2011). Here we report that mechanical forces on netrin-1 are necessary for chemoattraction and for the regulation of two intracellular mechanosensory proteins: focal adhesion kinase (FAK) and Crk-associated substrate (CAS) 


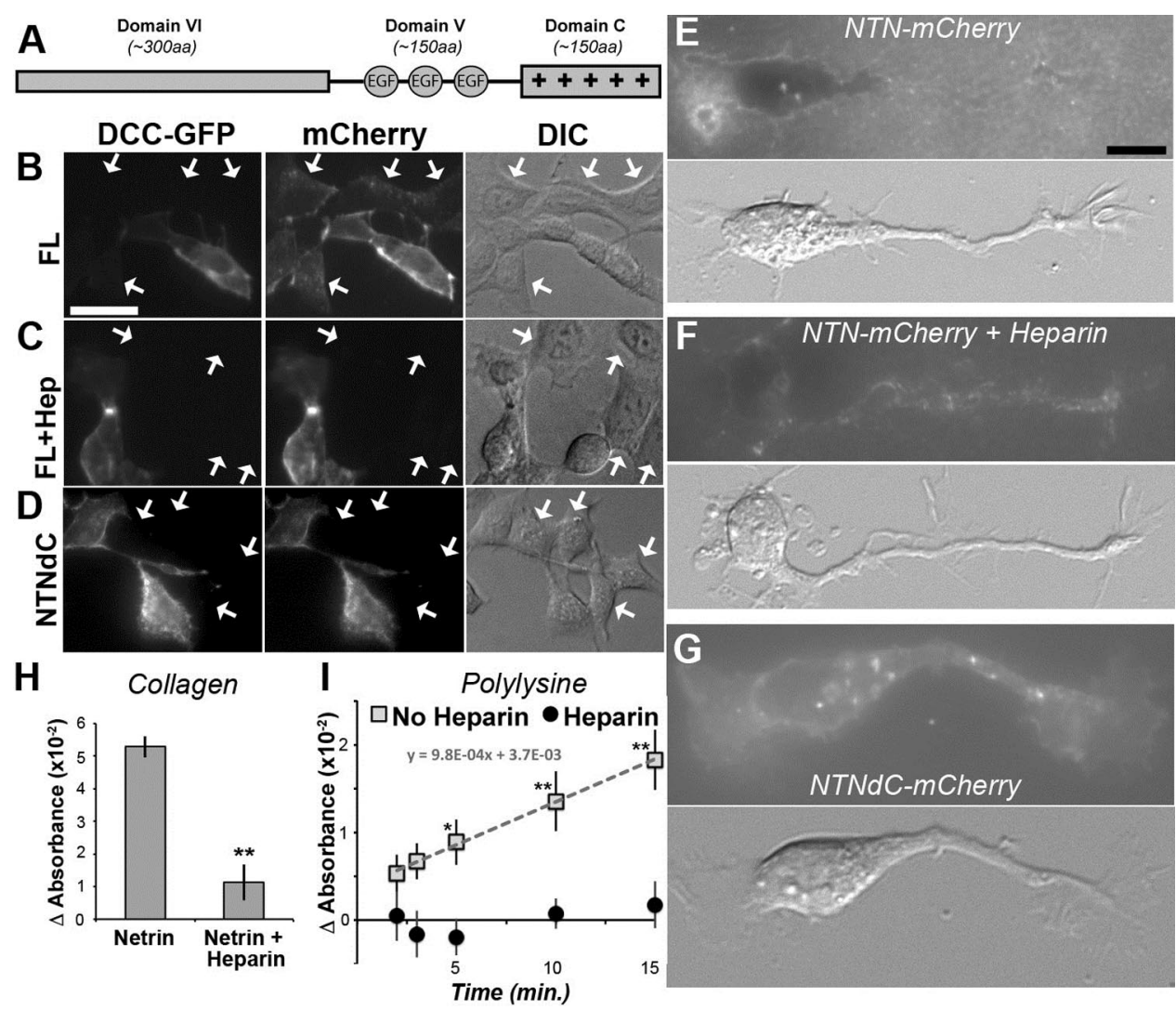

Figure 1. Heparin or deletion of domain C prevents nonspecific adsorption of netrin-1 but preserves DCC binding.A, Domain structure of netrin-1. Domain V and VI bind to netrin-1's receptor DCC, while domain C contributes to substrate adsorption through its many positively charged amino acids. $\boldsymbol{B}-\mathbf{D}$, HEK293 cells were transfected with GFP-tagged DCC (DCC-GFP) and incubated with either $1 \mu \mathrm{g} / \mathrm{ml}$ full-length mCherry-tagged netrin-1 (B), $1 \mu \mathrm{g} / \mathrm{ml}$ full-length NTN1-mCherry and $2 \mu \mathrm{g} / \mathrm{ml}$ heparin $(\boldsymbol{C})$, or $1 \mu \mathrm{g} / \mathrm{ml}$ NTN1dC (D) for 90 min. As highlighted by the cells that do not express DCC (white arrows), the presence heparin or deletion of domain ( restricts binding to only the cells that express DCC. $\boldsymbol{E}-\mathbf{G}$, Differential interference contrast (DIC) images (bottom) and unmodified

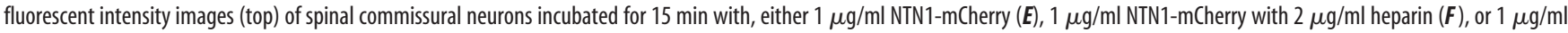
NTNdC-mCherry (G). Relative to full-length netrin applied alone, there is a decrease in background binding in the presence of heparin $(37 \%, p<0.01, n=40)$ or when domain C is deleted ( $20 \%$, $p<0.01, n=40$ ) and there is distinct labeling of both axon and growth cone. $\boldsymbol{H}, \boldsymbol{I}$, ELISA detecting the myc tag within recombinant, full-length netrin- 1 when media containing $200 \mathrm{ng} / \mathrm{ml}$ are incubated with either a collagen cushion for $16 \mathrm{~h}(\boldsymbol{H})$ or a polylysine-coated tissue culture well $(\boldsymbol{I})$ for time periods of $15 \mathrm{~min}$ or less. Significant binding of full-length netrin is seen to collagen gels $(n=16, p<0.01)$ and to polylysine dishes within $5 \mathrm{~min}(n>15, p<0.05)$ compared with media alone. Inclusion of $2 \mu \mathrm{g} / \mathrm{ml}$ heparin significantly reduced the association of netrin- 1 to collagen by $79 \%(n=16, p<0.01)$ and to a polylysine-coated dish by $90 \%$ after $15 \mathrm{~min}$. Fluorescent intensity comparison based on average intensities of $10 \mu \mathrm{m}^{2}$ areas from images of equal exposure $(5$ s). Scale bars: $B, 50 \mu \mathrm{m} ; \boldsymbol{E}, 10 \mu \mathrm{m}$.

\section{Materials and Methods}

Plasmids. A C-terminal, mCherry-tagged, full-length chicken netrin-1 (NTN1-mCherry) plasmid was generated through site-directed mutageneis (QuikChange II, Agilent) of the stop codon within pGNET1 (gift from Marc Tessier-Lavigne, Rockefeller University, New York, NY) and subcloning into pmCherry-N1 (Clontech). mCherry-tagged chicken netrin-1 lacking its entire C-terminal domain (amino acids 455-606m NTN1dC-mCherry) was generated through mutagenesis of NTN1mCherry. For electroporations, wild-type mouse FAK (pRc/CMV-FAK) and the FAK-Y397F mutant (pRc/CMV-FAK-397F; Calalb et al., 1995), chicken FAK C-terminal domain (FRNK; pcDNA3-FRNK; Lin et al., 1997), and pCS2-Venus (Nagai et al., 2002) were used. All plasmids were verified by sequencing.

Reagents. Full-length and truncated netrin-1 proteins were purified from stably transfected HEK 293 cells by liquid chromatography over a heparin column (HiTrap Heparin HP, GE Healthcare Life Sciences) using $0.1 \mathrm{~m}$ phosphate-buffered ( $\mathrm{pH}$ 7.4) $0.5 \mathrm{M} \mathrm{NaCl}$ and $2 \mathrm{M} \mathrm{NaCl}$. Polyclonal rabbit antibodies against the heavy chains of NMM-IIA were obtained as a gift from Dr. Robert Adelstein (National Institutes of Health, Bethesda, MD). Monoclonal antibody against NMM II-B (clone CMII 23) was from Developmental Studies Hybridoma Bank (University of Iowa, Iowa City, IA). Monoclonal anti- $\beta$-tubulin (clone 3F3-G2) was purchased from Santa Cruz Biotechnology. PP2, Blebbistatin, Y-27632 and ML-7 were purchased from EMD Biosciences. Antibodies against
FAK and CAS were obtained from BD Transduction Laboratories. Phosphospecific antibodies against CAS Y165 and Y410 were obtained from Cell Signaling Technology. Alexa Fluor 546-tagged phalloidin and phosphospecific antibodies against FAK Y397 and Y861 were obtained from Invitrogen. Antibodies against c-myc (9E10) and phosphorylated FAK Y576 were obtained from Santa Cruz Biotechnology. PF-573228 (PF228) was obtained from Tocris Bioscience. Heparin (grade I-A from procine intestinal mucosa, $17-19 \mathrm{kDa}$ ) was obtained from Sigma.

ELISA. For netrin-1 binding to type I collagen gels, typical outgrowth conditions were reproduced. Specifically, $10 \mu \mathrm{l}$ of collagen solution was allowed to gel for $30 \mathrm{~min}$ at the bottom in each well of a 96-well plate. Each well was then incubated at $37^{\circ} \mathrm{C}$ with $5 \% \mathrm{CO}_{2}$ with $100 \mu \mathrm{l}$ of Neurobasal/FBS media (see below). After $18 \mathrm{~h}$, each well was washed three times for 45 min with PBS with $0.1 \%$ BSA (and where appropriate, 2 $\mu \mathrm{g} / \mathrm{ml}$ heparin) and then fixed for $1 \mathrm{~h}$ in $4 \%$ paraformaldehyde/PBS. The wells were then blocked for $3 \mathrm{~h}$ in PBS with $0.1 \%$ BSA and $1 \%$ Triton $\mathrm{X}-100$. Labeling was achieved with sequential overnight incubations with 9E10 and HRP-tagged antibodies in PBS with 0.1\% BSA and 1\% Triton with at least six $1 \mathrm{~h}$ washes in between and after, followed by a final overnight wash.

For netrin-1 binding to polylysine-coated surfaces, typical culturing conditions were reproduced. Each well of a plasma-treated 96-well plate was incubated with $100 \mu \mathrm{l}$ of $2 \mu \mathrm{g} / \mathrm{ml}$ poly-L-lysine for an hour at room temperature and then washed several times with PBS. Each well was then 
incubated for $24 \mathrm{~h}$ with $100 \mu \mathrm{l}$ of Neurobasal/FBS media (see below) at $37^{\circ} \mathrm{C}$ with $5 \%$ $\mathrm{CO}_{2}$. Media containing $200 \mathrm{ng} / \mathrm{ml}$ netrin-1 and with in some cases $2 \mu \mathrm{g} / \mathrm{ml}$ heparin were then included for the indicated times. Each well was then washed with several changes of PBS, and then blocked for an hour at room temperature with $\mathrm{PBS}$ with $0.1 \%$ BSA, followed by $1 \mathrm{~h}$ at room temperature of incubations with $0.2 \mathrm{ng} / \mathrm{ml} \mathrm{9E10} \mathrm{and} \mathrm{then}$ HRP-tagged antibody with several washes of PBS in between. Colorimetric detection of $o$-phenylenediamine dihydrochloride (Pierce) was achieved by taking the absorbance at $450 \mathrm{~nm}$ after $30 \mathrm{~min}$.

Explants and dissociated cultures. Dissections of explants and dissociated spinal cultures were performed as described except that embryonic day 10 (E10; turning) or E12 (dorsal explants and dissociated cultures) CD1 mice embryos of both sexes were used (vaginal plug = E1; Moore and Kennedy, 2008). Culture media consisted of Neurobasal supplemented with $10 \%$ FBS, 2 mm GlutaMAX-1, $100 \mathrm{U} / \mathrm{ml}$ penicillin, and $100 \mu \mathrm{g} / \mathrm{ml}$ streptomycin (Neurobasal/FBS).

Electroporations. Plasmids were mixed at a 4:1 molar ratio with pCS2-Venus to a final concentration of $0.5 \mu \mathrm{g} / \mu \mathrm{l}$. Approximately $2 \mu \mathrm{l}$ of this DNA solution was injected into E12 mice spinal cords with the dorsal tissue still attached. Five $30 \mathrm{~V}$ pulses lasting $50 \mathrm{~ms}$ were applied via $3 \times 5 \mathrm{~mm}$ Genepaddles (Harvard Apparatus) attached to a BTX ECM 830 square wave electroporator (Harvard Apparatus). Following electroporation, the dorsal tissue was removed and spinal commissural neurons were isolated and cultured as described above.

Phosphoprotein analysis. Spinal commissural neurons were pretreated for $1 \mathrm{~h}$ with $50 \mu \mathrm{M}$ blebbistatin, $10 \mu \mathrm{M}$ PP2, or $10 \mu \mathrm{M}$ PF-228 and then for $15 \mathrm{~min}$ with $200 \mathrm{ng} / \mathrm{ml}$ netrin-1. For Western blot analysis, cells were lysed in radioimmunoprecipitation assay buffer (containing, in mM: 10 phosphate, $\mathrm{pH} 7.5,150 \mathrm{NaCl}$, $1 \%$ NP-40, 0.1\% SDS, $0.5 \%$ deoxycholate, 2 $\mu \mathrm{g} / \mathrm{ml}$ aprotinin, $5 \mu \mathrm{g} / \mathrm{ml}$ leupeptin, 1 EDTA, and 1 PMSF). For immunofluorescent analysis, cells were fixed with $37^{\circ} \mathrm{C} 4 \%$ paraformaldehyde/ $0.1 \%$ glutaraldehyde for $2 \mathrm{~min}$, followed by permeabilization ( $0.1 \%$ Triton), blocking ( $1 \% \mathrm{BSA})$, and antibody labeling in Tris-buffered saline solution. Coverslips were mounted with Slowfade (Invitrogen), immobilized with $2 \%$ agarose, and imaged immediately.

Optical trap assays. Proteins were covalently coupled to $2.3-\mu \mathrm{m}-$ diameter silica beads using cyanogen bromide (Technote \#205, Bangs Laboratories). Neurons were plated on PLL (poly-L-lysine, 30-70 kDa, Sigma)-coated $22 \times 22 \mathrm{~mm}$ coverslips (no. 1.5, Corning) in 6-well tissue culture dishes. Before assaying, neurons were preincubated for $1 \mathrm{~h}$ with 2 $\mu \mathrm{g} / \mathrm{ml}$ heparin and, where indicated, $50 \mu \mathrm{m}$ blebbistatin, $10 \mu \mathrm{M} \mathrm{Y}-27632$, $10 \mu \mathrm{M}$ ML-7, or $10 \mu \mathrm{M}$ PF-228. The optical trap was constructed using a 2W diode pumped $1064 \mathrm{~nm}$ laser (CrystalLaser) and calibrated using viscous drag (Dai and Sheetz, 1998). Cultured neurons on coverslips were enclosed into a $0.75-\mathrm{mm}$-thick sandwich, with media equilibrated to $37^{\circ} \mathrm{C}$ and $5 \% \mathrm{CO}_{2}$, that was sealed with vacuum grease and VALAP (McGee-Russell and Allen, 1971). Assays were performed at $37^{\circ} \mathrm{C}$ and within $1 \mathrm{~h}$ of mounting. The analysis of the dynamic motion of the bead within the trap was performed by a home-written correlation plug-in for ImageJ (Nanotrack).
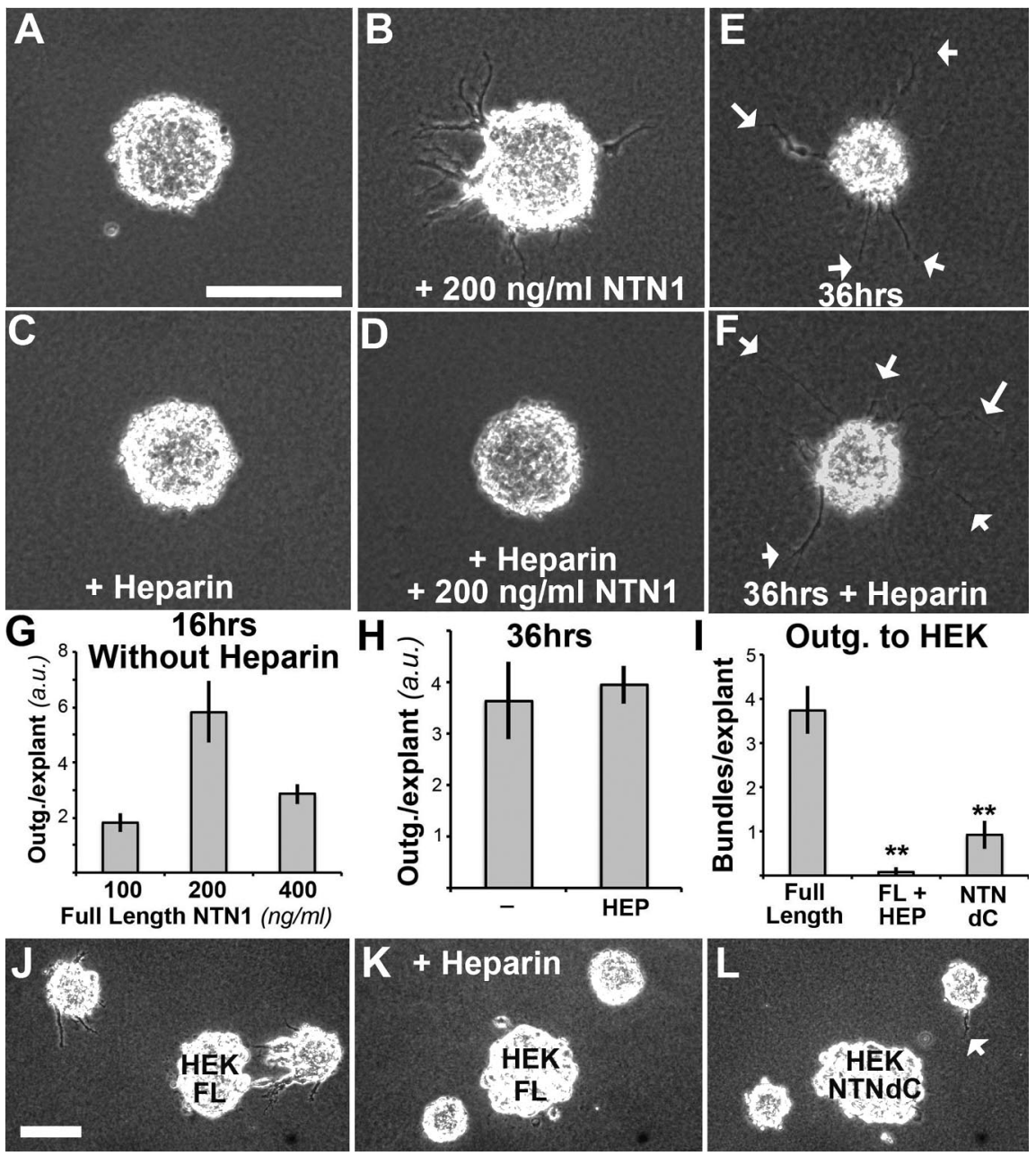

Figure 2. Substrate adsorption of netrin-1 is required for outgrowth from dorsal spinal cord explants. $\boldsymbol{A}-\boldsymbol{D}$, Dorsal spinal cord explants cultured for $16 \mathrm{~h}$ in a collagen gel. Netrin-1 (NTN1) elicits maximum outgrowth at $200 \mathrm{ng} / \mathrm{ml}(\boldsymbol{B}, \boldsymbol{G})$. However, when 2 $\mu \mathrm{g} / \mathrm{ml}$ heparin was coapplied to prevent substrate adsorption of netrin-1, all detectable outgrowth to netrin-1 was eliminated at , $400 \mathrm{ng} / \mathrm{ml}$ netrin-1 $(n>10$ explants, $\boldsymbol{D}) . \boldsymbol{E}, \boldsymbol{F}, \boldsymbol{H}$, The presence of heparin in the media had no effect on this netrin-independent outgrowth after $36 \mathrm{~h}$ (see white arrows in $\boldsymbol{E}$ and $\boldsymbol{F}, \boldsymbol{n}=4$ explants). $\boldsymbol{I} \boldsymbol{-} \boldsymbol{L}$, Transiently transfected HEK293 ggregates expressing either full-length netrin-1 (HEK FL) or netrin-1 lacking the substrate-binding, C-terminal domain (HEK $11, L)$ Outh $1, L)$. Outgrowth in $G$ and $H$ was quantified at the total length of bundles from each explant. Outgrowth to in $J-L$ was quantified as the number of bundles per explant. Scale bars, $100 \mu \mathrm{m}$.

\section{Results}

Coapplication of heparin or deletion of domain $\mathrm{C}$ reduces netrin-1 binding to substrates

Netrin-1 is a secreted protein of $\sim 600$ aa whose sequence can be divided into three domains: VI, V, and C (Fig. 1A). Domains VI and $\mathrm{V}$ are homologous to the $\gamma$-chain of laminin and mediate interaction with the netrin receptors DCC, UNC5, and dsCAM (Keino-Masu et al., 1996; Leonardo et al., 1997; Geisbrecht et al., 2003; Ly et al., 2008). Domain C has many basic amino acids and a predicted $\alpha$-helical secondary structure, and is homologous to domains found in the complement $\mathrm{C} 3,-4$, and -5 protein family, secreted frizzled-related proteins, type I C-proteinase enhancer proteins, and tissue inhibitors of metalloproteinases. In contrast to domains VI and V, domain C is not involved in binding the netrin receptors but, rather, electrostatically binds negatively charged glycosaminoglycans within the extracellular environment (Kappler et al., 2000; Yebra et al., 2003). As such, domain C 
A

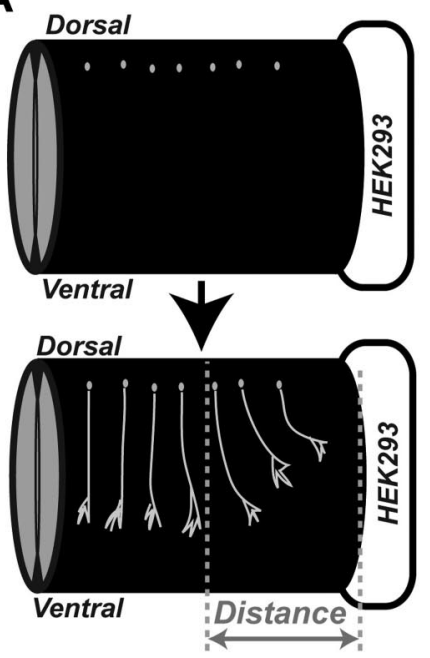

Full Length
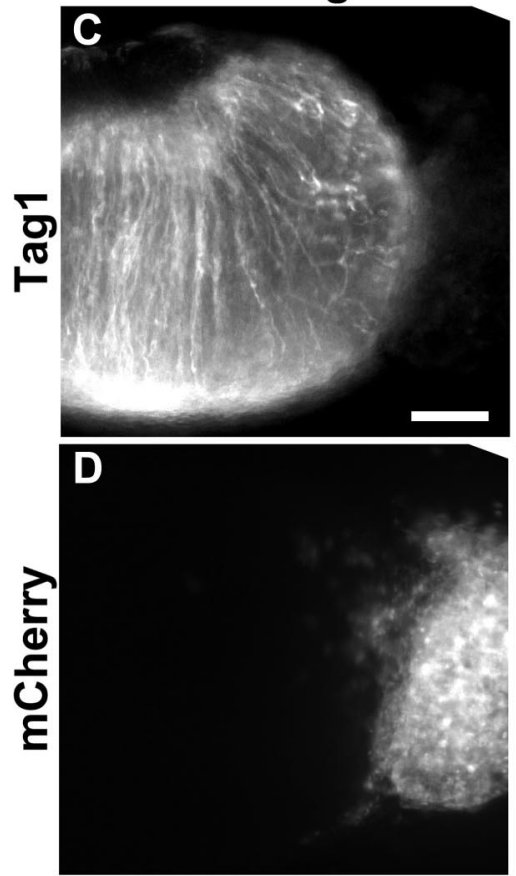

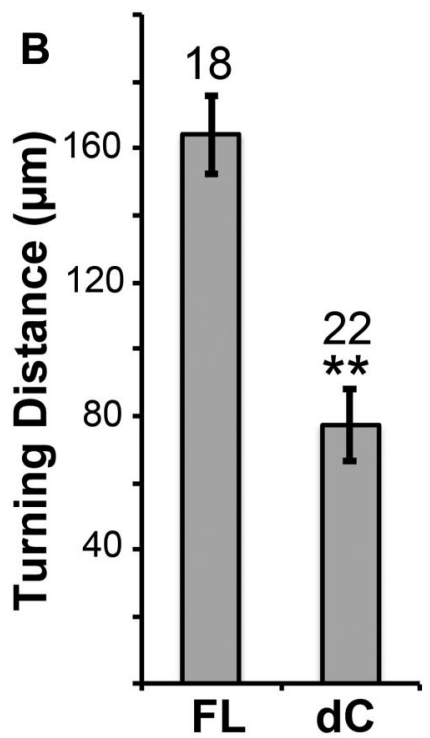

NTN1dC

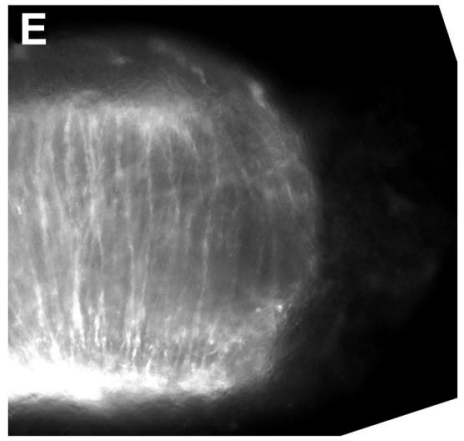

$F$

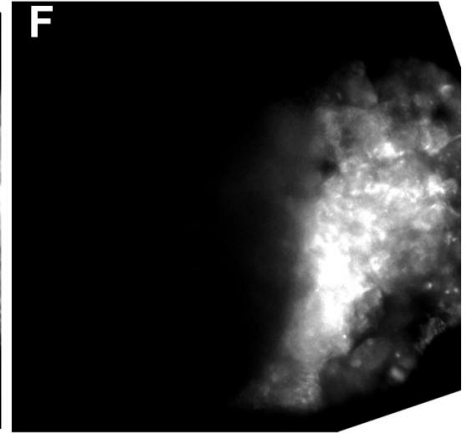

Figure 3. Substrate adsorption of netrin-1 is important for attracting spinal commissural neuron axons within the developing spinal cord. $\boldsymbol{A}$, Schematic of the turning assay whereby mouse E10 dorsal cord were dissected and cultured alongside aggregates of HEK293 cells expression either full-length or NTN1dC. $\boldsymbol{B}-\boldsymbol{D}$, HEK293-expressing full-length netrin-1 deflected axons over an average distance of $164 \mu \mathrm{m}(n=18) . \boldsymbol{B}, \boldsymbol{E}, \boldsymbol{F}$, However, when cellular aggregates expressed NTN1dC, the average distance decreased by $53 \%$ (mean of $77 \mu \mathrm{m}, n=22$ ). Scale bar, $100 \mu \mathrm{m}$. ${ }^{* *} p<0.01$ (least significant difference, LSD).

appears primarily responsible for nonspecific immobilization of netrin-1 to the extracellular environment.

To test the importance of this immobilization, we explored strategies that disrupted the binding of netrin-1 to surfaces, while leaving its interaction with known receptors unaffected. One approach was to coapply the negatively charged, heavily sulfated glycosaminoglycan heparin. Heparin inhibited nonspecific adsorption of netrin-1 to surfaces, but not its specific interactions with the DCC, UNC5, and dsCAM receptors (Keino-Masu et al., 1996; Leonardo et al., 1997; Geisbrecht et al., 2003; Ly et al., 2008). Importantly, when netrin-1 was covalently attached to a surface, the presence of soluble heparin was not disruptive to either DCC-mediated traction forces $>60 \mathrm{pN}$ or the attractive turning responses of spinal commissural neurons (Moore et al., 2009). Here we found that heparin did not disrupt binding of mCherry-tagged netrin-1 to HEK293 cells expressing GFPtagged DCC, but did reduce the nonspecific binding to cells that do not express DCC (Fig. $1 B, C$ ).

To further rule out the possibility that coapplication of heparin had effects in addition to maintaining netrin- 1 in a diffusible state, we developed mCherry-tagged netrin-1 (NTN1dC-mCherry) lacking the entire domain C (amino acids 455-606) based on similar constructs that had reduced substrate adsorption (Mirzayan, 1997; Geisbrecht et al., 2003). Consistent with a lower nonspecific binding affinity, the NTN1dC-mCherry construct eluted from a heparin column at $0.7 \mathrm{M} \mathrm{NaCl}$, which was considerably lower than the $1.2 \mathrm{M} \mathrm{NaCl}$ needed to elute full-length netrin- 1 . To determine whether domain $\mathrm{C}$ was necessary to support traction forces $>60 \mathrm{pN}$, we covalently attached NTN1dC-mCherry to beads that were applied to spinal commissural neuron growth cones using optical trapping. Traction forces of $>60 \mathrm{pN}$ were generated that were indistinguishable from those generated when full-length netrin-1 was used to coat beads $(n=6)$. Similar to coapplication of heparin with full-length netrin-1, we observed that NTN1dCmCherry bound specifically to cells expressing DCC and not to cells lacking DCC (Fig. $1 D)$. To examine whether coapplication of heparin or deletion of domain $\mathrm{C}$ preserved binding to DCC while reducing nonspecific binding to the substrate within spinal commissural neuron cultures, we fluorescently observed the binding of either full-length netrin-1 (NTN1-mCherry) or NTN1dCmCherry after $15 \mathrm{~min}$. We found that while full-length NTN1-mCherry bound to cell culture surfaces and neurons, coapplication of heparin or deletion of domain $\mathrm{C}$ biased binding to neurons (Fig. $1 E-G$ ). This indicated that binding to DCC expressed by spinal commissural neurons was preserved in the presence of heparin or upon deletion of domain C. Moreover, compared with when full-length netrin was applied alone, the fluorescent intensity of $10 \mu \mathrm{m}^{2}$ areas where no cells were present was significantly reduced in the presence of heparin $(37 \%, p<0.01, n=40)$ or upon deletion of domain C $(20 \%, p<0.01, n=40)$.

Reduced substrate absorption was also detected through an ELISA against the myc tag within recombinant netrin-1. We tested adsorption of full-length netrin-1 to type I collagen gels after a $16 \mathrm{~h}$ incubation, as well as upon acute addition to polylysine-coated cell culture surfaces that had been incubated for $24 \mathrm{~h}$ in culture media. These paradigms replicate commonly used assay conditions that test for netrin-1-induced outgrowth and intracellular biochemical events within dissociated neurons, re- 
spectively. Consistent with the ability of netrin-1 to adsorb to these surfaces, we found significant binding to type I collagen gels and a linear increase from 5 to 15 min in binding to polylysine-coated tissue culture surfaces (Fig. $1 H, I$ ). We then examined the ability of heparin to disrupt these nonspecific interactions. Indeed, we measured a $79 \%$ decrease in netrin-1 adsorption to collagen $(n=16, p<0.01)$ and a $90 \%$ decrease in the binding to polylysine-coated tissue culture plastic $(n>10, p<0.01$, Fig. $1 H, I)$. Therefore, coapplication of $2 \mu \mathrm{g} / \mathrm{ml}$ heparin or deletion of netrin-1 domain $\mathrm{C}$ effectively reduced nonspecific substrate adsorption of netrin-1 while preserving binding to its receptor DCC.

Netrin-1 immobilization is important for outgrowth and chemoattraction We then tested the importance of netrin-1 substrate adsorption in prototypical assays for netrin-1 function-axon outgrowth from dorsal spinal cord explants embedded in a collagen gel and turning of spinal commissural neuron axons within the developing spinal cord (Serafini et al., 1994). In the outgrowth assay, netrin-1 diffuses though collagen matrix to stimulate the explant; however, as shown in Figure $1 H$, netrin- 1 also adsorbs to collagen (Yebra et al., 2003). If a soluble form of netrin-1 was causing outgrowth, then blocking the binding of netrin-1 to collagen should not affect outgrowth. Normally, netrin-1 induces outgrowth when present at concentrations of 100, 200 and 400 ng/ml (Fig. 2G; Serafini et al., 1994). However, when adsorption of netrin-1 was prevented with coapplication of heparin, all detectable growth at each of these concentrations was eliminated $(n>10$ explants from three independent experiments, Fig. $2 A-D)$. Given the complete inhibition of outgrowth, it was important to verify that the general outgrowth potential of these explants was unaffected. Normal outgrowth occurs in the absence of netrin-1 by $36 \mathrm{~h}$ in culture. When explants were cultured in the absence of netrin-1 for $36 \mathrm{~h}$, heparin had no effect on this outgrowth (Fig. $2 E, F, H$ ). As a further test, we examined outgrowth evoked by HEK293 explants expressing full-length or netrin-1 lacking its substrate-binding domain (NTNdC). Normally, aggregates expressing full-length netrin-1 evoke robust outgrowth (3.9 bundles/explant). However, consistent with an important role for mechanical restraint of netrin-1, outgrowth was largely eliminated in the presence of $2 \mu \mathrm{g} / \mathrm{ml}$ heparin ( 0.1 bundles/
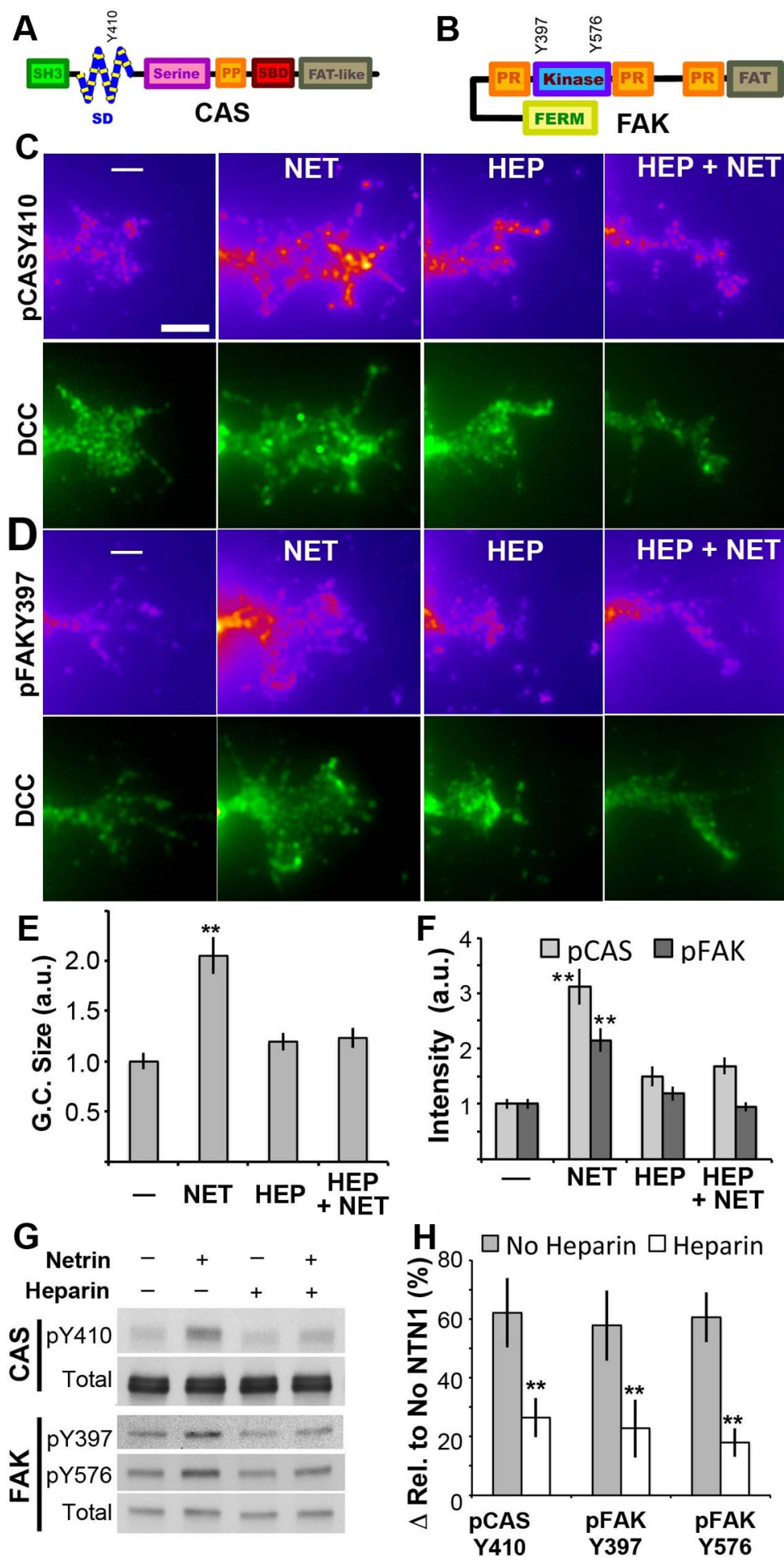

Figure 4. Netrin-1 Substrate adsorption is important for the phosphorylation of CAS and FAK. $\boldsymbol{A}, \boldsymbol{B}$, Diagrams of the domain structure of CAS and FAK showing the examined tyrosine phosphorylation sites within the substrate domain (SD) of CAS and the kinase domain of FAK. C, D, Top panels are immunofluorescent images of phosphorylated tyrosine 410 of CAS (pCASY410) or tyrosine 397 of FAK (pFAKY397) within spinal commissural growth cones. Brightness and contrast values are unmodified, but to highlight intensity differences, gray scale images were converted to the "Fire" LUT (Look Up Table) of ImageJ. Bottom panels show DCC labeling. $\boldsymbol{E}$, Normally, netrin-1 increases average growth cones area approximately doubles (2.1-fold, $n=60, p<0.01)$ after $15 \mathrm{~min}$ with $200 \mathrm{ng} / \mathrm{ml}$ netrin-1. However, reducing substrate adsorption of netrin with $2 \mu \mathrm{g} / \mathrm{ml}$ heparin disrupts this expansion $(n=60)$ as measured based on DCC staining. $\boldsymbol{F}$, Addition of netrin- 1 increases the integrated density of pCASY410 (3.1-fold, $n=$ 50 ) and pFAK397 (2.2-fold $n=50$ ) labeling. Coapplication of heparin significantly reduced the pCASY410 by 54\% (1.7-fold of baseline), $n=49$ ) and pFAKY397 by 44\% (1.0-fold of baseline, $n=47)$. G, Westem blot images from spinal commissural neuron (SCN) cultures for FAK and CAS phosphorylation following 15 min stimulation with $200 \mathrm{ng} / \mathrm{ml}$ netrin-1. $\boldsymbol{H}$, Quantification of the change in netrin-induced phosphorylation relative to the absence of netrin. The presence of heparin significantly reduced the amount of CAS-Y410 $(57 \%, n=6)$, FAK-Y397 $(61 \%, n=8)$ and FAK-Y576 $(71 \%, n=6)$ phosphorylation. ${ }^{* *} p<0.01$ (LSD). Scale bar, $5 \mu \mathrm{m}$. 

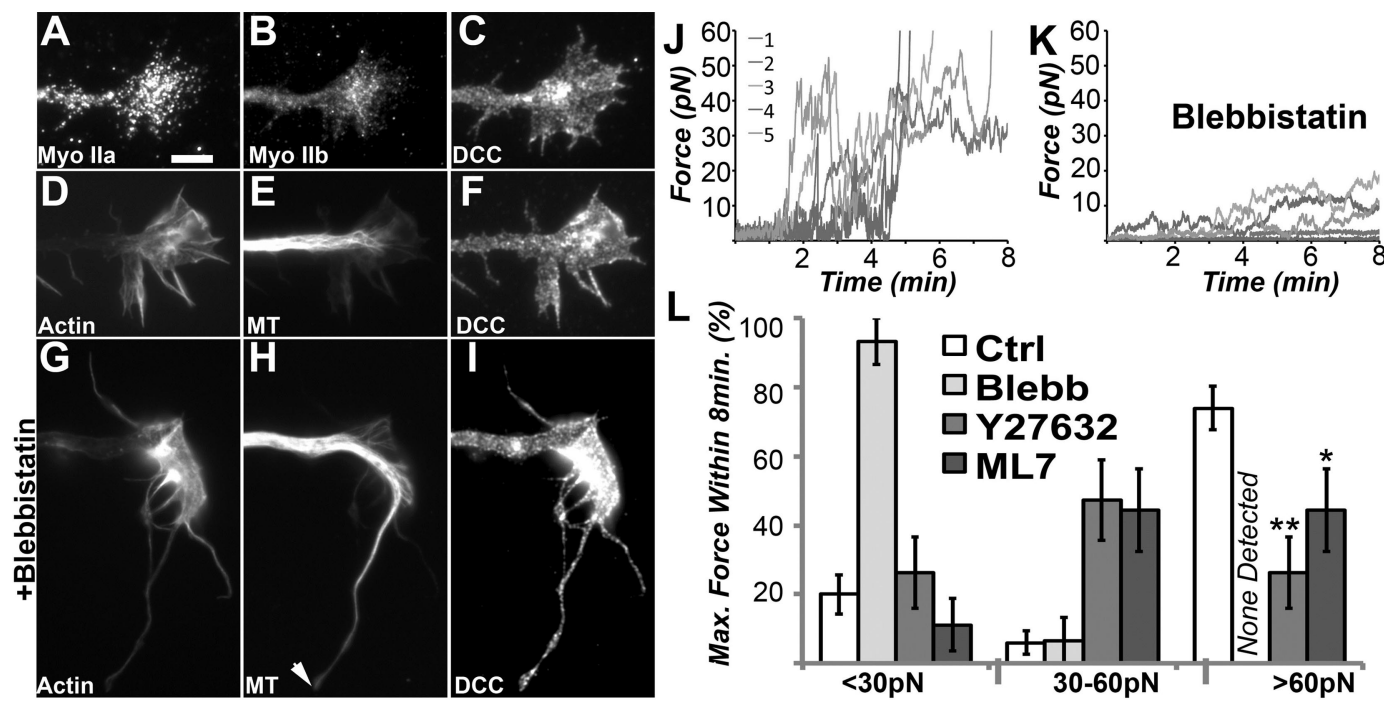

Figure 5. Myosin II is required for traction on Netrin-1. A-C, Immunofluorescent labeling of myosin lla and Ilb shows enrichment in the central region of the growth cone. D-F, Normally microtubule filaments are concentrated in the central region of normal growth cones, while actin filaments are found throughout. G-I, However, inhibition of myosin Il with $50 \mu \mathrm{m}$ blebbistatin for $1 \mathrm{~h}$ resulted in growth cones with dramatically longer filopodia and dense microtubule arrays that penetrate deep into the peripheral region of the growth cone (arrow).J, $K$, Five representative plots of the amount of force over time exerted on netrin-1-coated beads normally $(J)$ and in the presence of $50 \mu \mathrm{m}$ blebbistatin $(K)$. $L$, Growth cone pulling forces on netrin- 1 within 8 min of initial contact were categorized into three responses: $<30 \mathrm{pN}$, between 30 and $60 \mathrm{pN}$, and $>60 \mathrm{pN}$. Typically, approximately three quarters of spinal commissural neuron growth cones exert $>60 \mathrm{pN}$ offorce on netrin-1 within 8 min $(74 \%, n=50)$. However, inthe presence of the myosin Il inhibitor blebbistatin (Blebb) not a single growth cone was able to generate $>60 \mathrm{pN}$. Instead the vast majority generated $<30 \mathrm{pN}(93 \%, n=15)$. Similarly, significantly less growth cones exerted $>60 \mathrm{pN}$ in the presence of Y-27632 $(47 \%, n=19)$ and ML7 $(44 \%, n=18) .{ }^{*} p<0.05,{ }^{* *} p<0.01$ relative to Ctrl (LSD). Scale bar, $5 \mu \mathrm{m}$.

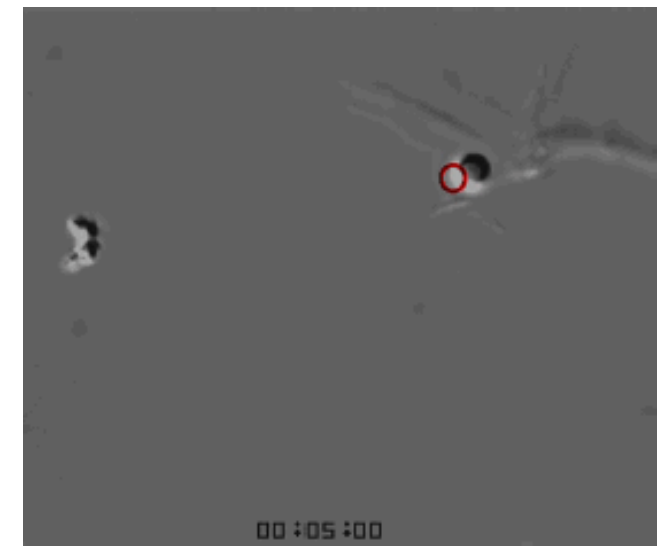

Movie 1. Normal pulling of netrin-1. Normal pulling of an optically trapped $2.3 \mu \mathrm{m}$ bead coated with netrin-1 by a spinal commissural neuron growth cone. The red circle denotes the center of the trap. Note the recruitment of additional contacts and expansion of the growth cone after 3 min that leads to extraction of the bead from the trap after $\sim 5$ min. Time stamp $=$ hh:mm:ss.

explant) or when the aggregates expressed NTNdC ( 0.9 bundles/ explant, Fig. $2 I-L)$.

We then examined the importance of substrate adsorption on the chemoattractive ability of netrin- 1 within the developing spinal cord. To test this, we used an assay whereby the spinal cord was dissected at a time before spinal commissural neurons extended. When explants of either the floor plate or aggregates of cells expressing chemotactic cues are cultured on the rostral or caudal edge, commissural neurons are deflected from their normally parallel dorsal-ventral trajectory (Fig. 3A; Moore and Kennedy, 2008). Consistent with an important role for netrin-1 adsorption during chemoattraction to netrin- 1 within the developing spinal cord, we observed a 53\% reduction in the distance over which spinal commissural axons were deflected to a source of netrin-1 lacking the substrate-binding domain C ( $n \geq 18$, Fig.

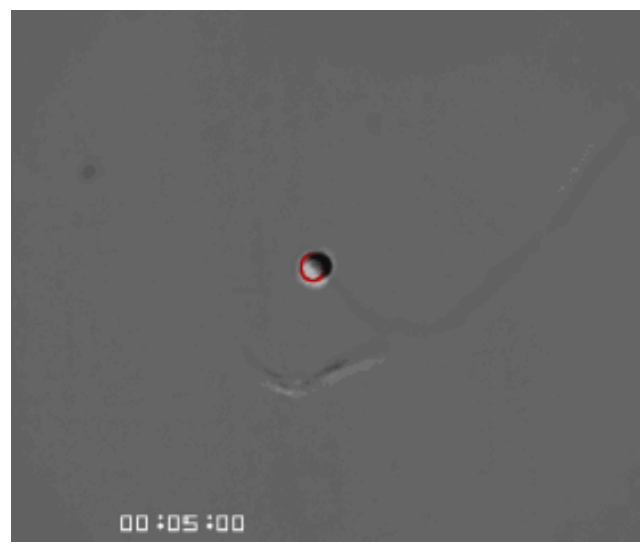

Movie 2. Inhibition of myosin II disrupts forces on netrin-1. Pulling of an optically trapped $2.3 \mu \mathrm{m}$ bead coated with netrin- 1 by a spinal commissural neuron growth cone in the presence of the myosin Il inhibitor blebbistatin. The red circle denotes the center of the trap. Note the long filopodia that move laterally but not retrogradely, as well as, the much smaller forces generated on the bead (as evidenced by the much smaller displacement of the bead from the center of the trap). Time stamp $=$ hh:mm:ss.

$3 B-F)$. Together, these observations demonstrate that netrin-1 binding to surfaces is important for both its outgrowthpromoting and chemoattractive effects on spinal commissural neuron axons.

\section{Substrate binding of netrin-1 is important for the activation of CAS and FAK}

The importance of substrate adsorption was consistent with a role for mechanotransduction in the response to netrin-1. If this was indeed the case, then the intracellular signaling pathways linked to netrin-1 chemoattraction should also be dependent on the mechanical pulling forces on netrin-1. In axon chemoattraction settings, netrin-1 regulates numerous intracellular pathways (Moore et al., 2007; Lai Wing Sun et al., 2011). In those experi- 

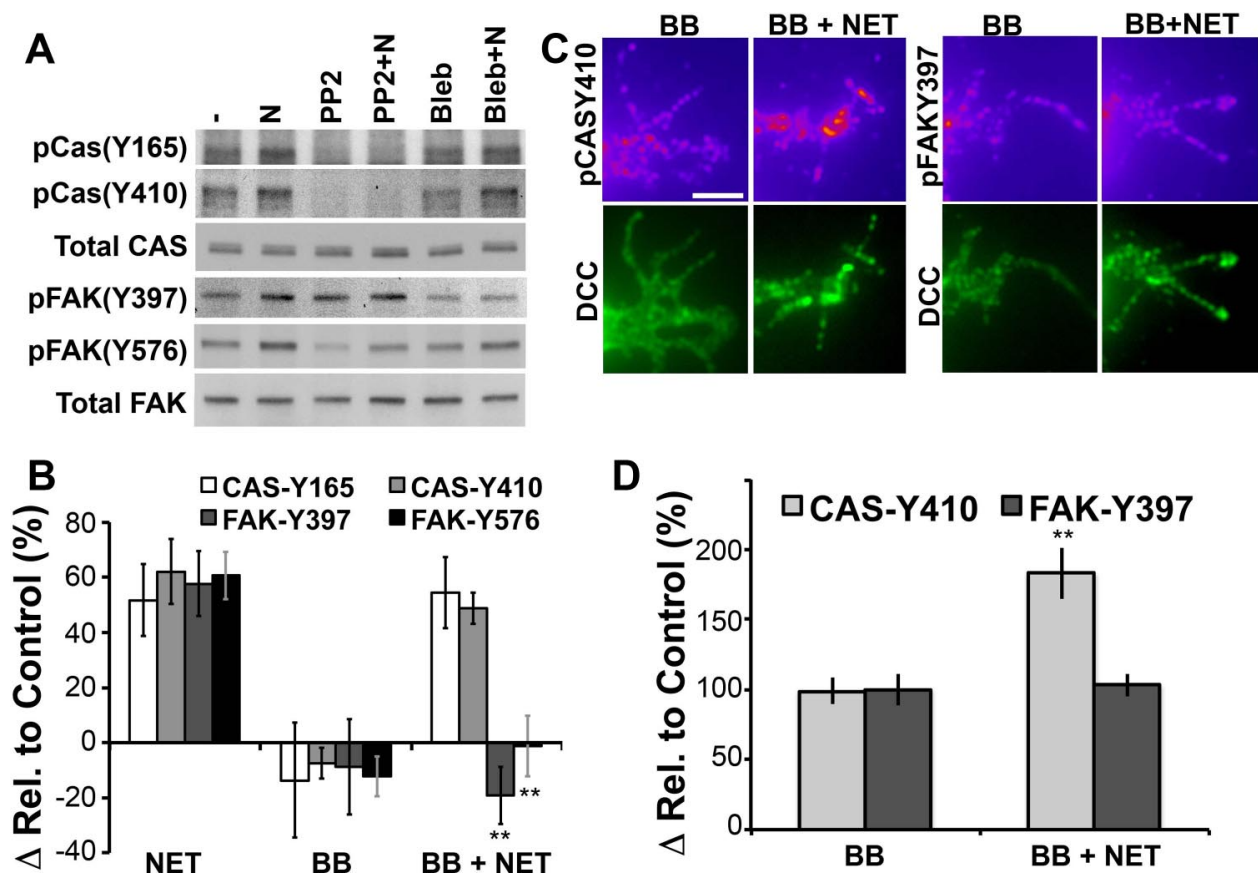

Figure 6. Myosin II contractions underlie netrin-1-induced FAK Phosphorylation. A, Western blot images of tyrosine phosphorylation within the substrate domain of CAS (Y165 and Y410) or the kinase domain of FAK (Y397 and Y576) following 15 min netrin stimulations $(200 \mathrm{ng} / \mathrm{ml})$ in the absence of inhibitors or following preincubation for $1 \mathrm{~h}$ with the Src Family Kinase inhibitor PP2 (10 $\mu \mathrm{M}$ ) or the myosin II inhibitor blebbistatin (50 $\mu \mathrm{m}$, blebb). B, Quantification of netrin-1 stimulated phosphorylation intensity changes relative to control cells (in the absence of both netrin and blebbistatin). Inhibition of myosin II reduced netrin-1-induced phosphorylation of FAK on the Y397 and Y576 sites by $77 \%(n=8)$ and $62 \%(n=5)$, respectively. No significant effects were seen on the netrin-1-induced phosphorylation within the substrate domain of CAS (Y165 and Y410). C, Top panels are immunofluorescent images of phosphorylated tyrosine 410 of CAS (pCASY410) and tyrosine 397 of FAK (pFAKY397) within spinal commissural growth cones. Brightness and contrast values are unmodified, but to highlight intensity differences, gray scale images were converted to the Fire LUT of ImageJ. Bottom panels show DCC labeling. $\boldsymbol{D}$, Inhibition of myosin prevented an increase in the integrated density of FAK-Y397, but not of CAS-Y410, labeling $(n=50$ for each condition) relative to control (in the absence of both netrin and blebbistatin). ${ }^{* *} p<0.01$ (LSD). Scale bar, $5 \mu \mathrm{m}$.

ments, soluble netrin- 1 was added to the culture media and the biochemical consequences were typically analyzed within $15 \mathrm{~min}$. This acute application of netrin-1 to the media could indicate a soluble, unrestrained role. However, as shown in Figure $1 \mathrm{I}$, detectable netrin- 1 adsorption occurred to these cell culture surfaces within $5 \mathrm{~min}$. To determine the importance of mechanically restrained netrin-1 under these acute conditions, we examined the consequences of preventing absorption on netrin-1's ability to expand of spinal commissural neuron growth cones within 15 min (Shekarabi et al., 2005). Consistent with an important role for restrained netrin-1, we found that disrupting adsorption with heparin prevented the expansion of growth cones (Fig. 4C-E).

We then explored the possibility that the intracellular signaling cascades activated by netrin-1 were dependent on mechanically restrained netrin-1. Previous studies had found that the phosphorylation of CAS (p130Cas, BCAR1) and FAK (Ptk2) were increased upon acute (15 min) addition of netrin-1 (Li et al., 2004; Liu et al., 2004, 2007; Ren et al., 2004). In the case of CAS, netrin-1 addition promoted phosphorylation of tyrosine 410 within CAS's substrate domain (pY410, Fig. 4A). Phosphorylation of tyrosines within this substrate domain underlie CAS's ability to function as a mechanosensor (Sawada et al., 2006). In terms of FAK, netrin-1 increased phosphorylation on tyrosines 397 (Y397) and 576 (Y576) (Fig. 4B). The Y397 site is an autophosphorylated site that upon phosphorylation is recognized by the SH2 domains of several Src family kinases (SFKs) (Schaller et al., 1994), while the Y576 site is phosphorylated by SFKs and is thought to promote FAK kinase activity (Calalb et al., 1995).

We confirmed that netrin induced phosphorylation of these sites within CAS and FAK in dissociated spinal commissural neurons. Using Western blot analysis, we found that netrin-1 in- creased the phosphorylation within the substrate domain of CAS (Y410) by $62 \%(n=18)$, and FAK phosphorylation by $58 \%$ on Y397 $(n=18)$ and by $61 \%$ on Y576 $(n=14$; Fig. $4 G, H)$. Similarly, immunofluorescent detection of their growth cones demonstrated a 3.1-fold increase in the phosphorylation of CAS-Y410 $(n=50)$ and a 2.2-fold increase in FAK-Y397 $(n=50$; Fig. $4 C, D, F)$. When the adsorption of netrin- 1 to the surface was then blocked by coapplication of heparin, the level of phosphorylation of each of the sites on CAS and FAK was dramatically decreased. By Western blot, the relative increase in the presence of heparin was reduced by $57 \%(n=6)$ on CAS-Y 410 , by $61 \%(n=8)$ on FAK-Y397, and by 71\% $(n=6)$ on FAK-Y576. Immunofluorescent detection of their growth cones revealed a $54 \%(n=49)$ reduction of CAS-Y410 phosphorylation and a $44 \%(n=47)$ reduction of FAK autophosphorylation (Y397). Thus, mechanical restraint of netrin-1 has an important role in the activation of the major signaling pathways of CAS and FAK.

\section{Traction on netrin-1 requires myosin II activity}

If the phosphorylation of CAS and FAK is indeed a mechanosensory process, traction forces on netrin-1 could be triggering their phosphorylation. If so, inhibition of force on netrin- 1 should inhibit phosphorylation. According to the "substrate to cytoskeleton" model of axon extension, traction forces are generated when liganded extracellular matrix receptors are bridged to retrogradely flowing actin (Suter and Forscher, 2000). In neuronal growth cones, non-muscle myosin II transports actin rearward (Brown and Bridgman, 2003). We found an enrichment of myosin IIa and IIb within the central domain of the growth cones in spinal commissural neurons (Fig. $5 A-C$ ). When blebbistatin, a small molecule inhibitor that locked the myosin II head in a 

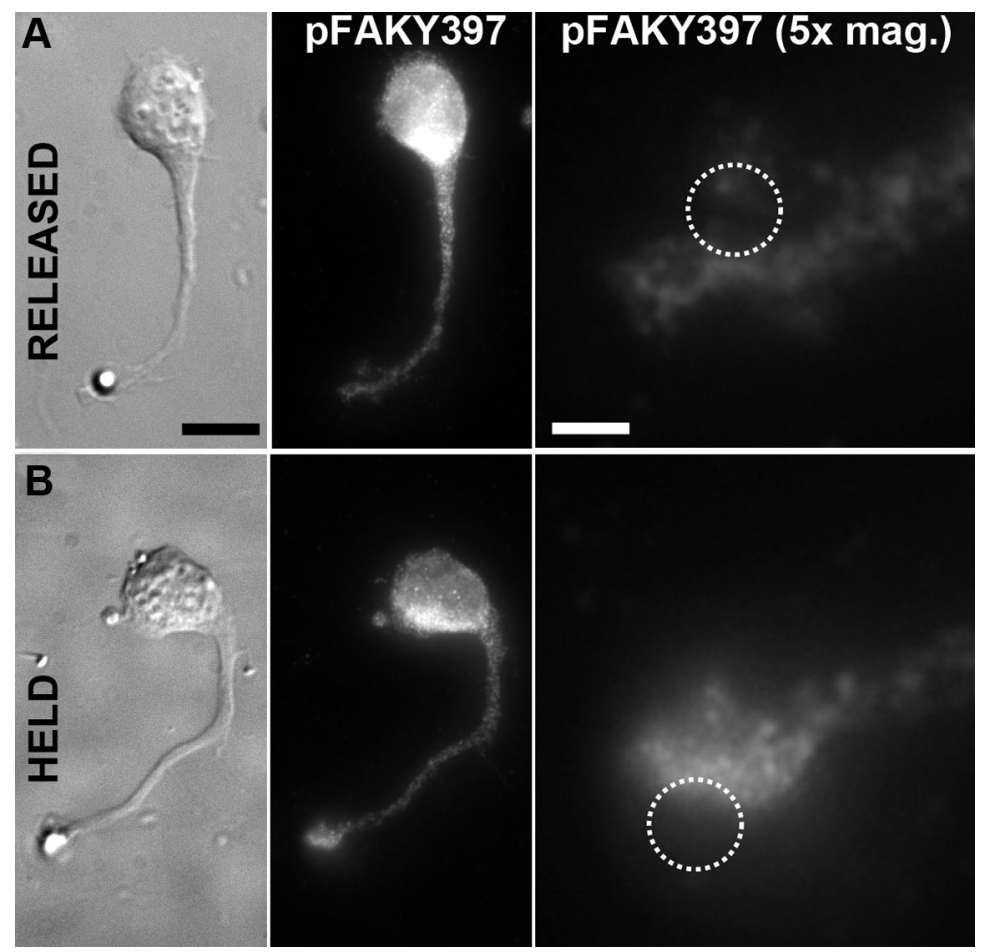

Figure 7. $\quad A, B$, Mechanical force on netrin-1 triggers FAK autophosphorylation. DIC and immunofluorescent images of spinal commissural neurons that were presented with netrin-1-coated beads, then fixed and immunofluorescently processed for FAK autophosphorylation (pFAKY397). In one scenario the bead was released from the optical trap 15-30 s after its initial contact with the growth cone and then processed $5^{\prime}$ later $(\boldsymbol{A})$. In the other scenario, the bead was held for the entire $5^{\prime}$ period thus allowing the growth cone to build $>30 \mathrm{pN}$ of force on the bead $(\boldsymbol{B})$. The average immunofluorescent signal within each growth cone was normalized to the average intensity of a $5 \mu \mathrm{m}^{2}$ area of the axon segment immediately adjacent to the growth cone. When Netrin-1-coated beads were held $(\boldsymbol{B})$ there was a $63 \%$ ( $n=13$, $p<0.05$ ) increase in FAK Y397 autophosphorylation within the growth cone compared with when it is released $(\boldsymbol{A})$. Brightness levels of immunofluorescent images are unmodified. Dotted circle denotes the location of the bead. Scale bars are $10 \mu \mathrm{m}$ (left) and $2 \mu \mathrm{m}$ (right).

low actin affinity conformation (Kovács et al., 2004), was added to growth cones, waves of actin stopped moving rearward and the average length of growth cone filopodia grew from $2.2 \mu \mathrm{m}$ to $7.9 \mu \mathrm{m}(n>40, p<0.01)$. Further, microtubules extended into the growth cone's periphery (Fig. $5 D-I$ ). Thus, inhibition of myosin II contraction should inhibit mechanical force generation on adhesion sites coupled to actin flow.

To determine whether the traction forces on netrin-1 were dependent on myosin II activity, we presented spinal commissural neurons with optically trapped beads coated with netrin-1. Normally, growth cones both progressively increase the number of contacts with the bead and pull in excess of $60 \mathrm{pN}$ within $8 \mathrm{~min}$ (Fig. 5J; Movie 1; Moore et al., 2009). When myosin II activity was inhibited with blebbistatin, filopodia were still capable of lateral movement (Movie 2). However, none of the growth cones examined generated forces $>60 \mathrm{pN}$ on netrin-1 beads and the vast majority (93\%) generated forces $<30 \mathrm{pN}$ (Fig. $5 \mathrm{~K}, L$ ). When myosin activity was indirectly inhibited through inhibition of myosin light chain kinase (with ML-7) or Rho-associated kinase (with Y-27632), pulling of netrin-1 was also inhibited, but less efficiently (Fig. $5 L$ ). Thus, inhibition of myosin II through blebbistatin treatment is an effective strategy to eliminate traction forces on netrin- $1>30 \mathrm{pN}$.

Traction forces are required for netrin-induced phosphorylation of FAK, but not of CAS

If forces $>30 \mathrm{pN}$ on netrin-1 are involved in the phosphorylation of CAS and FAK, then inhibition of myosin II activity should reduce the phosphorylation levels. We found that inhibition of myosin II reduced the ability of netrin-1 to elevate FAK phosphorylation. Specifically, by Western blot analysis, we found that blebbistatin reduced netrin-1-triggered FAK autophosphorylation (Y397) by 77\% $(n=$ 8 ) and phosphorylation on Y576 by $62 \%$ $(n=5$; Fig. $6 A, B)$. Similarly, immunofluorescence for FAK-Y397 phosphorylation within the growth cones revealed no significant difference upon netrin-1 stimulation when myosin II was inhibited (Fig. $6 C, D)$. In contrast to FAK, phosphorylation of CAS's substrate domain was unaffected by myosin II inhibition. We observed that inhibiting myosin II had no significant effect on the phosphorylation state of either CAS Y165 or Y410 by either Western blot analysis or immunofluorescence within the growth cone (Fig. $6 A-D)$.

Because myosin II inhibition disrupted traction forces $>30 \mathrm{pN}$, the above Western blotting and immunofluorescence data indicated that traction forces activated FAK phosphorylation. To further test this hypothesis, netrin-1-coated beads were presented to growth cones for 5 min with either a brief restraint (15-30 s) or with restraint throughout. We then used immunofluorescence techniques to detect FAK autophosphorylation within the growth cones (Fig. 7). We found a $63 \%$ increase $(n=13, p<0.05)$ in the amount of FAK autophosphorylation within the growth cones when beads were restrained for $5^{\prime}$ and growth cones were allowed to build larger forces $(>30$ $\mathrm{pN}$ ) on the beads. Thus, myosin II contractile force on netrin-1 has an important role in the activation of FAK at the site of attachment.

\section{FAK's kinase activity builds traction forces on netrin}

In fibronectin adhesions, force production on fibronectin stabilizes adhesions and results in greater force production (Choquet et al., 1997). Similarly, activation of the FAK kinase by force on substrate-bound netrin-1 may cause strengthening of the netrin-1 adhesion, resulting in greater force generation on netrin-1. When the FAK-specific inhibitor PF-228 (Slack-Davis et al., 2007) was added, both endogenous and netrin-1stimulated autophosphorylation of FAK was inhibited (Fig. 8A). Further, PF-228 addition caused a dramatic (86\%) reduction in the number of growth cones that exerted traction forces $>60 \mathrm{pN}$ on netrin-1 (Fig. $8 \mathrm{~B}$ ). Because PF-228 may have affected other enzymes, we used the expression of FRNK or FAK-Y397F to inhibit FAK function in spinal commissural neurons. FRNK is a variant of FAK that lacks the FERM and kinase domains, but has the proline-rich and focal adhesion targeting domains responsible for binding p130Cas and DCC (Fig. 8C; Harte et al., 1996; Ren et al., 2004). FAK-Y397F is a mutant of FAK with its Y397 autophosphorylation site mutated to phenylalanine, thus impairing the recruitment of numerous proteins including Src family kinases (Schaller et al., 1994). Although transient expression of wild-type FAK had no effect on traction forces on netrin-1 beads, 
expression of FRNK and FAK-Y397F reduced the fraction of growth cones that exerted $>60 \mathrm{pN}$ of force on netrin- 1 by 56 and $69 \%$, respectively (Fig. $8 D$ ). Thus, the activation of the FAK kinase is an important step in the generation of high forces $(>60 \mathrm{pN})$ on netrin-1.

To gain further insight into the underlying cause of the reduced pulling force, we carefully examined the growth cone's interactions with an optically trapped netrin-1-coated bead. Normally, initial filopodial contacts with netrin-1 beads grew in area through the recruitment of additional filopodia and/or engulfment by the growth cone's lamellipodium within $8 \mathrm{~min}$ (Movie 1). When the activity of the growth cone filopodia was monitored before and after netrin- 1 bead binding, there was a clear increase in the number of filopodia that contact and are stabilized onto the bead. Pharmacological and genetic inhibition of FAK disrupted that activation and recruitment process in a manner that mirrored the reduction in pulling forces (Fig. $8 E, F$ ). Therefore, disrupting FAK function reduced the expansion of adhesions between the growth cone and netrin-1 beads.

\section{Discussion}

These findings define several important steps in the process of axon guidance to netrin-1. First, in contrast to unrestrained netrin-1, substrate-bound netrin-1 supports axon outgrowth, growth cone expansion, and chemoattractive signaling through FAK and CAS. Second, myosin II-dependent traction forces on netrin-1 activate FAK's kinase activity. Third, FAK kinase activity produces increased traction force on netrin-1 through the expansion of filopodial contacts. Thus, we suggest that guidance to netrin- 1 is mediated by a gradient of substrate-attached netrin- 1 and not a soluble gradient.

\section{Substrate attachment of netrin-1 in axon guidance}

The ability of pulsatile release of netrin-1

from a pipette to guide axons could be regarded as evidence of a guidance activity of freely diffusible netrin-1 (de la Torre et al., 1997; Ming et al., 1997). However, there are several lines of evidence that it is substrate-adsorbed netrin- 1 that is guiding axons in these assays. First, there is rapid adsorption of netrin-1 (within $5 \mathrm{~min}$ ) to polylysine-coated surfaces (Fig. 1I). We have also directly observed binding of netrin-1 using fluorescently coupled netrin-1 that was pulsed for $30 \mathrm{~min}$ from a pipette onto glass surfaces that were incubated for $12 \mathrm{~h}$ with Xenopus spinal neuron culture media (49\% L15, 50\% Ringer's, $1 \%$ fetal bovine serum; S. W. Moore and M. P. Sheetz, unpublished observations). Finally, our evidence that disrupting substrate adsorption of
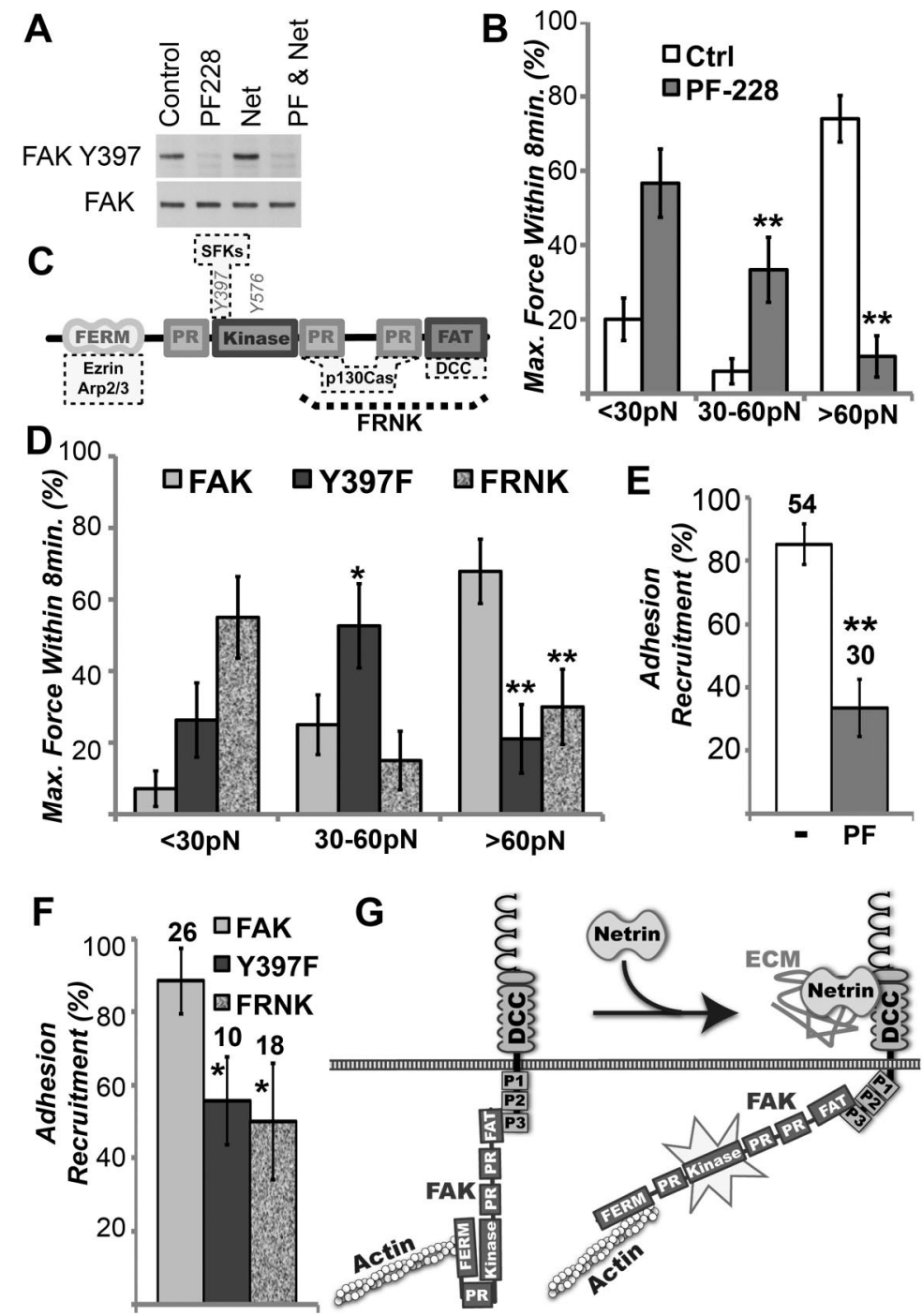

Figure 8. Inhibition of FAK disrupts strong traction forces on netrin-1. A, Western blot images of the autophosphorylation site domain. $\boldsymbol{D}$, Overexpression of FAK had no significant effect on the ability of growth cones to pull on netrin-1 with $>60 \mathrm{pN}(70 \%$, $n=23)$. However, fewer axons generated $>60 \mathrm{pN}$ on netrin- 1 when expressing FAK-Y397F $(22 \%, n=18)$ or FRNK $(35 \%, n=$ expanded their initial contacts on the netrin-1 beads. Adhesion expansion was quantified as the number of filopodia whose contacts are stabilized on the bead. Numbers above each bar represent the number of growth cones examined for each condition. $G$, A possible mechanism whereby traction force on netrin activates FAK's kinase activity through separation of FAK's FERM domain from the kinase domain. The C-terminal FAT domain of FAK associates with the P3 intracellular domain of DCC, while its $\mathrm{N}$-terminal FERM domain indirectly associates with actin filaments. ${ }^{*} p<0.05,{ }^{* *} p<0.01$ relative to $C \operatorname{trl}(\boldsymbol{B}, \boldsymbol{E})$ or $F A K(\boldsymbol{D}, \boldsymbol{F})(\mathrm{LSD})$.

netrin-1 reduces outgrowth (Fig. 2), turning (Fig. 3), and intracellular activation of FAK and CAS (Figs. 4-7) suggests that it is substrate-bound netrin-1 that guides axons in these pipette axonturning assays.

The dependence upon substrate binding raises the question of what netrin-1 adsorbs to in vivo. In the developing retina, netrin-1 is closely associated with the glial cells that produce it (Deiner et al., 1997). In the developing spinal cord, there is an exponential decrease in density of netrin-1 more than $\sim 250 \mu \mathrm{m}$ from its source (Kennedy et al., 2006). Prime binding sites for netrin-1 are the glycosaminoglycans found on both extracellular matrix and cell surface proteins. They are emerging as key regu- 
lators of axon guidance cue function (de Wit and Verhaagen, 2007). The heparan sulfate polymerizing enzyme Ext1, like netrin-1 and DCC, is required for proper formation of major commissural tracts (Serafini et al., 1996; Fazeli et al., 1997; Inatani and Yamaguchi, 2003). When heparan sulfate proteoglycan (HSPG) expression is disrupted within spinal commissural neurons, there is a disruption of axon fasciculation (Matsumoto et al., 2007). As such, HSPGs both on netrin-attractive axons and along their trajectory are likely to provide substrate attachment sites for netrin in vivo.

\section{FAK as a mechanosensor in a variety of contexts}

Mechanical force induces tyrosine phosphorylation of FAK in aortic endothelial cells, tracheal smooth muscle, and fibroblasts (Yano et al., 1996; Tang et al., 1999; Zhang et al., 2008), and blocking FAK Y397 phosphorylation using antibodies disrupts flow-induced dilation of coronary arteries (Koshida et al., 2005). In the absence of FAK, fibroblasts have reduced migration rates and altered responses to applied force, as well as impaired rigidity sensing and traction forces on collagen substrates (Wang et al., 2001). Therefore, FAK appears to function as a mechanosensor in a variety of cellular contexts. In terms of axon guidance, FAK has also been implicated in the guidance of axons to a growing number of cues, including: ephrins, Sema-3s, and brain-derived neurotrophic factor (BDNF) (Ren et al., 2004; Falk et al., 2005; Woo and Gomez, 2006). Notably, each of these cues are physically restrained; Ephrins span the plasma membrane or are GPIlinked, while Sema-3s and BDNF are secreted but are known to bind to extracellular matrix components (De Wit et al., 2005; Liang et al., 2010; Martino and Hubbell, 2010). As such, FAK may have a ubiquitous function as a mechanosensor in the response to these guidance cues.

\section{Mechanism of FAK activation}

There is mounting evidence that the activation of FAK is through mechanical extraction of the FERM domain from its kinase domain. The FERM domain has been shown to interact with and inhibit its kinase domain (Cooper et al., 2003). Using fluorescent resonance energy transfer-based sensors in fibroblasts, conformational changes of the FERM domain have been detected in growing integrin adhesions (Cai et al., 2008; Papusheva et al., 2009). As mentioned above, FAK tyrosine phosphorylation is mechanically induced in a variety of cellular contexts (Yano et al., 1996; Tang et al., 1999; Zhang et al., 2008; Pasapera et al., 2010), and crystal structures have demonstrated that when FAK is phosphorylated, the FERM domain no longer blocks access to the catalytic site (Lietha et al., 2007). The N-terminal FERM domain of FAK interacts with the f-actin binding proteins Ezrin and the Arp2/3 complex (Poullet et al., 2001; Serrels et al., 2007), while the C-terminal focal adhesion targeting (FAT) domain interacts with netrin-1's receptor DCC (Ren et al., 2004). As such, one possible mechanism of FAK activation is that it experiences traction forces that extract the FERM domain from its kinase domain (Fig. 8G).

\section{FAK in both adhesion assembly and disassembly}

Deletion of FAK leads to a greater number of focal adhesions in fibroblasts (Ilić et al., 1995) and reintroduction reduces steadystate traction forces (Dumbauld et al., 2010). On the other hand, several reports have shown that FAK activity is required for early events in adhesion formation in both fibroblasts and neuronal growth cones (Robles and Gomez, 2006; Michael et al., 2009). Therefore, FAK is implicated in both the assembly and disassem- bly of adhesions. Similarly, the guidance of growth cones is a multistep process that involves both adhesion assembly and disassembly. While FAK has a significant role in the guidance of axons to netrin-1 (Liu et al., 2004), it is not clear from those studies how FAK is involved. Based upon these studies, it is clear that myosin II mechanical forces are critical in activating FAK and FAK activity is important for increasing the force on netrin-1 through the recruitment of additional contacts.

\section{CAS as a myosin II-independent mechanosensor}

The precise role of CAS in cell migration and axonal extension remains largely unclear. CAS deficient fibroblasts have reduced spreading and migration rates on a variety of substrates (Honda et al., 1999; Carter et al., 2002; Sanders and Basson, 2005; Tazaki et al., 2008). In terms of axon extension and guidance, disruption of CAS slows extension rates and reduces the ability of axons to chemoattract to netrin-1 (Huang et al., 2006; Liu et al., 2007). Interestingly, while there are CAS homologues in vertebrates and Drosophila, no homolog exists in Caenorhabditis elegans, where netrin is known to have an evolutionary conserved axon guidance function (Hedgecock et al., 1990; Singh et al., 2008). Thus, the role of CAS in axon attraction to netrin-1 may not be ubiquitous but, rather, may indicate there are different control or effector systems.

CAS and FAK appear to cooperate in certain cellular eventsthey bind each other and their ligand-induced phosphorylation requires proper actin organization in a variety of contexts (Nojima et al., 1995; Vuori and Ruoslahti, 1995; Ojaniemi and Vuori, 1997). However, we found that, while inhibition of myosin II reduces phosphorylation of FAK (on both Y397 and Y576), it does not significantly affect CAS phosphorylation (Fig. 6). Conversely, inhibition of SFKs reduces CAS phosphorylation but does not significantly affect FAK Y397 phosphorylation. As such there are independent pathways that activate FAK kinase activity and CAS phosphorylation. Importantly, both require substratebound netrin-1, which is consistent with both being downstream of mechanosensory activation (Fig. 4). Determining the cellular events that trigger CAS phosphorylation is therefore an important topic to address.

\section{Conclusion}

Guidance of growth cones to netrin-1 involves a mechanosensing process in the link between substrate-bound netrin-1 and the actomyosin contractile network. FAK and CAS have important roles in the steps of guidance that follow initial binding and involve further recruitment of receptors to areas with substrate bound netrin-1. In such a multistep process, there must be a coordination of many motile systems and a rigid netrin-1 cue provides a simple way to guide the process.

\section{References}

Bashaw GJ, Klein R (2010) Signaling from axon guidance receptors. Cold Spring Harb Perspect Biol 2:a001941.

Brankatschk M, Dickson BJ (2006) Netrins guide Drosophila commissural axons at short range. Nat Neurosci 9:188-194.

Brown J, Bridgman PC (2003) Role of myosin II in axon outgrowth. J Histochem Cytochem 51:421-428.

Cai X, Lietha D, Ceccarelli DF, Karginov AV, Rajfur Z, Jacobson K, Hahn KM, Eck MJ, Schaller MD (2008) Spatial and temporal regulation of focal adhesion kinase activity in living cells. Mol Cell Biol 28:201-214.

Calalb MB, Polte TR, Hanks SK (1995) Tyrosine phosphorylation of focal adhesion kinase at sites in the catalytic domain regulates kinase activity: a role for Src family kinases. Mol Cell Biol 15:954-963.

Carter N, Nakamoto T, Hirai H, Hunter T (2002) EphrinA1-induced cyto- 
skeletal re-organization requires FAK and p130(cas). Nat Cell Biol 4:565-573.

Choquet D, Felsenfeld DP, Sheetz MP (1997) Extracellular matrix rigidity causes strengthening of integrin-cytoskeleton linkages. Cell 88:39-48.

Cooper LA, Shen TL, Guan JL (2003) Regulation of focal adhesion kinase by its amino-terminal domain through an autoinhibitory interaction. Mol Cell Biol 23:8030-8041.

Dai J, Sheetz MP (1998) Chapter 09: Cell membrane mechanics. Methods Cell Biol 55:157-171.

Davenport RW, Dou P, Rehder V, Kater SB (1993) A sensory role for neuronal growth cone filopodia. Nature 361:721-724.

Deiner MS, Kennedy TE, Fazeli A, Serafini T, Tessier-Lavigne M, Sretavan DW (1997) Netrin-1 and DCC mediate axon guidance locally at the optic disc: loss of function leads to optic nerve hypoplasia. Neuron 19:575-589.

de la Torre JR, Höpker VH, Ming GL, Poo MM, Tessier-Lavigne M, Hemmati-Brivanlou A, Holt CE (1997) Turning of retinal growth cones in a netrin-1 gradient mediated by the netrin receptor DCC. Neuron 19:1211-1224.

de Wit J, Verhaagen J (2007) Proteoglycans as modulators of axon guidance cue function. Adv Exp Med Biol 600:73-89.

De Wit J, De Winter F, Klooster J, Verhaagen J (2005) Semaphorin 3A displays a punctate distribution on the surface of neuronal cells and interacts with proteoglycans in the extracellular matrix. Mol Cell Neurosci 29:40-55.

Dumbauld DW, Shin H, Gallant ND, Michael KE, Radhakrishna H, García AJ (2010) Contractility modulates cell adhesion strengthening through fo$\mathrm{cal}$ adhesion kinase and assembly of vinculin-containing focal adhesions. J Cell Physiol 223:746-756.

Falk J, Julien F, Bechara A, Fiore R, Nawabi H, Zhou H, Hoyo-Becerra C, Bozon M, Rougon G, Grumet M, Püschel AW, Sanes JR, Castellani V (2005) Dual functional activity of semaphorin 3B is required for positioning the anterior commissure. Neuron 48:63-75.

Fazeli A, Dickinson SL, Hermiston ML, Tighe RV, Steen RG, Small CG, Stoeckli ET, Keino-Masu K, Masu M, Rayburn H, Simons J, Bronson RT, Gordon JI, Tessier-Lavigne M, Weinberg RA (1997) Phenotype of mice lacking functional Deleted in colorectal cancer (Dcc) gene. Nature 386:796-804.

Geisbrecht BV, Dowd KA, Barfield RW, Longo PA, Leahy DJ (2003) Netrin binds discrete subdomains of DCC and UNC5 and mediates interactions between DCC and heparin. J Biol Chem 278:32561-32568.

Harte MT, Hildebrand JD, Burnham MR, Bouton AH, Parsons JT (1996) p130Cas, a substrate associated with v-Src and v-Crk, localizes to focal adhesions and binds to focal adhesion kinase. J Biol Chem 271:13649-13655.

Hedgecock EM, Culotti JG, Hall DH (1990) The unc-5, unc-6, and unc-40 genes guide circumferential migrations of pioneer axons and mesodermal cells on the epidermis in C. elegans. Neuron 4:61-85.

Hoffman BD, Grashoff C, Schwartz MA (2011) Dynamic molecular processes mediate cellular mechanotransduction. Nature 475:316-323.

Honda H, Nakamoto T, Sakai R, Hirai H (1999) p130(Cas), an assembling molecule of actin filaments, promotes cell movement, cell migration, and cell spreading in fibroblasts. Biochem Biophys Res Commun 262:25-30.

$\mathrm{Hu} \mathrm{H}$ (2001) Cell-surface heparan sulfate is involved in the repulsive guidance activities of Slit2 protein. Nat Neurosci 4:695-701.

Huang J, Sakai R, Furuichi T (2006) The docking protein Cas links tyrosine phosphorylation signaling to elongation of cerebellar granule cell axons. Mol Biol Cell 17:3187-3196.

Huber AB, Kolodkin AL, Ginty DD, Cloutier JF (2003) Signaling at the growth cone: ligand-receptor complexes and the control of axon growth and guidance. Annu Rev Neurosci 26:509-563.

Ilić D, Furuta Y, Kanazawa S, Takeda N, Sobue K, Nakatsuji N, Nomura S, Fujimoto J, Okada M, Yamamoto T (1995) Reduced cell motility and enhanced focal adhesion contact formation in cells from FAK-deficient mice. Nature 377:539-544.

Inatani M, Yamaguchi Y (2003) Gene expression of EXT1 and EXT2 during mouse brain development. Brain Res Dev Brain Res 141:129-136.

Kappler J, Franken S, Junghans U, Hoffmann R, Linke T, Müller HW, Koch KW (2000) Glycosaminoglycan-binding properties and secondary structure of the C-terminus of netrin-1. Biochem Biophys Res Commun 271:287-291.

Keino-Masu K, Masu M, Hinck L, Leonardo ED, Chan SS, Culotti JG, Tessier-
Lavigne M (1996) Deleted in Colorectal Cancer (DCC) encodes a netrin receptor. Cell 87:175-185.

Kennedy TE, Serafini T, de la Torre JR, Tessier-Lavigne M (1994) Netrins are diffusible chemotropic factors for commissural axons in the embryonic spinal cord. Cell 78:425-435.

Kennedy TE, Wang H, Marshall W, Tessier-Lavigne M (2006) Axon guidance by diffusible chemoattractants: a gradient of netrin protein in the developing spinal cord. J Neurosci 26:8866-8874.

Koshida R, Rocic P, Saito S, Kiyooka T, Zhang C, Chilian WM (2005) Role of focal adhesion kinase in flow-induced dilation of coronary arterioles. Arterioscler Thromb Vasc Biol 25:2548-2553.

Kovács M, Tóth J, Hetényi C, Málnási-Csizmadia A, Sellers JR (2004) Mechanism of blebbistatin inhibition of myosin II. J Biol Chem 279:35557-35563.

Lai Wing Sun K, Correia JP, Kennedy TE (2011) Netrins: versatile extracellular cues with diverse functions. Development 138:2153-2169.

Lamoureux P, Buxbaum RE, Heidemann SR (1989) Direct evidence that growth cones pull. Nature 340:159-162.

Leonardo ED, Hinck L, Masu M, Keino-Masu K, Ackerman SL, TessierLavigne M (1997) Vertebrate homologues of C. elegans UNC-5 are candidate netrin receptors. Nature 386:833-838.

Liang W, Han Q, Jin W, Xiao Z, Huang J, Ni H, Chen B, Kong J, Wu J, Dai J (2010) The promotion of neurological recovery in the rat spinal cord crushed injury model by collagen-binding BDNF. Biomaterials 31:8634-8641

Li W, Lee J, Vikis HG, Lee SH, Liu G, Aurandt J, Shen TL, Fearon ER, Guan JL, Han M, Rao Y, Hong K, Guan KL (2004) Activation of FAK and Src are receptor-proximal events required for netrin signaling. Nat Neurosci 7:1213-1221.

Lietha D, Cai X, Ceccarelli DFJ, Li Y, Schaller MD, Eck MJ (2007) Structural basis for the autoinhibition of focal adhesion kinase. Cell 129:1177-1187.

Lin TH, Aplin AE, Shen Y, Chen Q, Schaller M, Romer L, Aukhil I, Juliano RL (1997) Integrin-mediated activation of MAP kinase is independent of FAK: evidence for dual integrin signaling pathways in fibroblasts. J Cell Biol 136:1385-1395.

Liu G, Beggs H, Jürgensen C, Park HT, Tang H, Gorski J, Jones KR, Reichardt LF, Wu J, Rao Y (2004) Netrin requires focal adhesion kinase and Src family kinases for axon outgrowth and attraction. Nat Neurosci $7: 1222-1232$.

Liu G, Li W, Gao X, Li X, Jürgensen C, Park HT, Shin NY, Yu J, He ML, Hanks SK, Wu JY, Guan KL, Rao Y (2007) p130CAS is required for netrin signaling and commissural axon guidance. J Neurosci 27:957-968.

Ly A, Nikolaev A, Suresh G, Zheng Y, Tessier-Lavigne M, Stein E (2008) DSCAM is a netrin receptor that collaborates with DCC in mediating turning responses to netrin-1. Cell 133:1241-1254.

Mai J, Fok L, Gao H, Zhang X, Poo MM (2009) Axon initiation and growth cone turning on bound protein gradients. J Neurosci 29:7450-7458.

Manitt C, Kennedy TE (2002) Where the rubber meets the road: netrin expression and function in developing and adult nervous systems. Prog Brain Res 137:425-442.

Martino MM, Hubbell JA (2010) The 12th-14th type III repeats of fibronectin function as a highly promiscuous growth factor-binding domain. FASEB J 24:4711-4721.

Matsumoto Y, Irie F, Inatani M, Tessier-Lavigne M, Yamaguchi Y (2007) Netrin-1/DCC signaling in commissural axon guidance requires cellautonomous expression of heparan sulfate. J Neurosci 27:4342-4350.

McGee-Russell S, Allen R (1971) Reversible stabilization of labile microtubules in the reticulopodial network of allogromia. Adv Cell Mol Biol 1:153-184.

Michael KE, Dumbauld DW, Burns KL, Hanks SK, García AJ (2009) Focal adhesion kinase modulates cell adhesion strengthening via integrin activation. Mol Biol Cell 20:2508-2519.

Ming GL, Song HJ, Berninger B, Holt CE, Tessier-Lavigne M, Poo MM (1997) cAMP-dependent growth cone guidance by netrin-1. Neuron 19:1225-1235.

Mirzayan C (1997) Molecular mechanisms underlying the response of commissural axons to netrin-1 (UMI: 9818659) (Tessier-Lavigne M, ed). University of California, San Francisco.

Moore SW, Kennedy TE (2008) Dissection and culture of embryonic spinal commissural neurons. Curr Protoc Neurosci Chapter 3:Unit3.20.

Moore SW, Sheetz MP (2011) Biophysics of substrate interaction: influence 
on neural motility, differentiation, and repair. Dev Neurobiol 71:1090-1101.

Moore SW, Tessier-Lavigne M, Kennedy TE (2007) Netrins and their receptors. Adv Exp Med Biol 621:17-31.

Moore SW, Biais N, Sheetz MP (2009) Traction on immobilized netrin-1 is sufficient to reorient axons. Science 325:166.

Moore SW, Roca-Cusachs P, Sheetz MP (2010) Stretchy proteins on stretchy substrates: the important elements of integrin-mediated rigidity sensing. Dev Cell 19:194-206.

Nagai T, Ibata K, Park ES, Kubota M, Mikoshiba K, Miyawaki A (2002) A variant of yellow fluorescent protein with fast and efficient maturation for cell-biological applications. Nat Biotechnol 20:87-90.

Nojima Y, Morino N, Mimura T, Hamasaki K, Furuya H, Sakai R, Sato T, Tachibana K, Morimoto C, Yazaki Y (1995) Integrin-mediated cell adhesion promotes tyrosine phosphorylation of p130Cas, a Src homology 3-containing molecule having multiple Src homology 2-binding motifs. J Biol Chem 270:15398-15402.

Ojaniemi M, Vuori K (1997) Epidermal growth factor modulates tyrosine phosphorylation of p130Cas. Involvement of phosphatidylinositol 3'kinase and actin cytoskeleton. J Biol Chem 272:25993-25998.

Papusheva E, Mello de Queiroz F, Dalous J, Han Y, Esposito A, JaresErijmanxa EA, Jovin TM, Bunt G (2009) Dynamic conformational changes in the FERM domain of FAK are involved in focal-adhesion behavior during cell spreading and motility. J Cell Sci 122:656-666.

Pasapera AM, Schneider IC, Rericha E, Schlaepfer DD, Waterman CM (2010) Myosin II activity regulates vinculin recruitment to focal adhesions through FAK-mediated paxillin phosphorylation. J Cell Biol 188:877-890.

Poullet P, Gautreau A, Kadaré G, Girault JA, Louvard D, Arpin M (2001) Ezrin interacts with focal adhesion kinase and induces its activation independently of cell-matrix adhesion. J Biol Chem 276:37686-37691.

Raper J, Mason C (2010) Cellular strategies of axonal pathfinding. Cold Spring Harb Perspect Biol 2:a001933.

Ren XR, Ming GL, Xie Y, Hong Y, Sun DM, Zhao ZQ, Feng Z, Wang Q, Shim S, Chen ZF, Song HJ, Mei L, Xiong WC (2004) Focal adhesion kinase in netrin-1 signaling. Nat Neurosci 7:1204-1212.

Rider CC (2006) Heparin/heparan sulphate binding in the TGF-beta cytokine superfamily. Biochem Soc Trans 34:458-460.

Robles E, Gomez TM (2006) Focal adhesion kinase signaling at sites of integrin-mediated adhesion controls axon pathfinding. Nat Neurosci 9:1274-1283.

Sanders MA, Basson MD (2005) p130cas but not paxillin is essential for Caco-2 intestinal epithelial cell spreading and migration on collagen IV. J Biol Chem 280:23516-23522.

Sawada Y, Tamada M, Dubin-Thaler BJ, Cherniavskaya O, Sakai R, Tanaka S, Sheetz MP (2006) Force sensing by mechanical extension of the Src family kinase substrate p130Cas. Cell 127:1015-1026.

Schaller MD, Hildebrand JD, Shannon JD, Fox JW, Vines RR, Parsons JT (1994) Autophosphorylation of the focal adhesion kinase, pp125FAK, directs SH2-dependent binding of pp60src. Mol Cell Biol 14:1680-1688.

Serafini T, Kennedy TE, Galko MJ, Mirzayan C, Jessell TM, Tessier-Lavigne M (1994) The netrins define a family of axon outgrowth-promoting proteins homologous to C. elegans UNC-6. Cell 78:409-424.
Serafini T, Colamarino SA, Leonardo ED, Wang H, Beddington R, Skarnes WC, Tessier-Lavigne M (1996) Netrin-1 is required for commissural axon guidance in the developing vertebrate nervous system. Cell 87:1001-1014.

Serrels B, Serrels A, Brunton VG, Holt M, McLean GW, Gray CH, Jones GE, Frame MC (2007) Focal adhesion kinase controls actin assembly via a FERM-mediated interaction with the Arp $2 / 3$ complex. Nat Cell Biol 9:1046-1056.

Shekarabi M, Moore SW, Tritsch NX, Morris SJ, Bouchard JF, Kennedy TE (2005) Deleted in colorectal cancer binding netrin-1 mediates cell substrate adhesion and recruits Cdc42, Rac1, Pak1, and N-WASP into an intracellular signaling complex that promotes growth cone expansion. J Neurosci 25:3132-3141.

Singh MK, Dadke D, Nicolas E, Serebriiskii IG, Apostolou S, Canutescu A, Egleston BL, Golemis EA (2008) A novel Cas family member, HEPL, regulates FAK and cell spreading. Mol Biol Cell 19:1627-1636.

Slack-Davis JK, Martin KH, Tilghman RW, Iwanicki M, Ung EJ, Autry C, Luzzio MJ, Cooper B, Kath JC, Roberts WG, Parsons JT (2007) Cellular characterization of a novel focal adhesion kinase inhibitor. J Biol Chem 282:14845-14852.

Suter DM, Forscher P (2000) Substrate-cytoskeletal coupling as a mechanism for the regulation of growth cone motility and guidance. J Neurobiol 44:97-113.

Tang D, Mehta D, Gunst SJ (1999) Mechanosensitive tyrosine phosphorylation of paxillin and focal adhesion kinase in tracheal smooth muscle. Am J Physiol 276:C250-C258.

Tazaki T, Miyazaki K, Hiyama E, Nakamoto T, Sakai R, Yamasaki N, Honda Z, Noda M, Miyasaka N, Sueda T, Honda H (2008) Functional analysis of Src homology 3 -encoding exon (exon 2) of p130Cas in primary fibroblasts derived from exon 2-specific knockout mice. Genes Cells 13:145-157.

Vuori K, Ruoslahti E (1995) Tyrosine phosphorylation of p130Cas and cortactin accompanies integrin-mediated cell adhesion to extracellular matrix. J Biol Chem 270:22259-22262.

Wang HB, Dembo M, Hanks SK, Wang Y (2001) Focal adhesion kinase is involved in mechanosensing during fibroblast migration. Proc Natl Acad Sci U S A 98:11295-11300.

Woo S, Gomez TM (2006) Racl and RhoA promote neurite outgrowth through formation and stabilization of growth cone point contacts. J Neurosci 26:1418-1428.

Yano Y, Geibel J, Sumpio BE (1996) Tyrosine phosphorylation of pp125FAK and paxillin in aortic endothelial cells induced by mechanical strain. Am J Physiol 271:C635-C649.

Yebra M, Montgomery AMP, Diaferia GR, Kaido T, Silletti S, Perez B, Just ML, Hildbrand S, Hurford R, Florkiewicz E, Tessier-Lavigne M, Cirulli V (2003) Recognition of the neural chemoattractant Netrin-1 by integrins alpha6beta4 and alpha3betal regulates epithelial cell adhesion and migration. Dev Cell 5:695-707.

Zhang X, Jiang G, Cai Y, Monkley SJ, Critchley DR, Sheetz MP (2008) Talin depletion reveals independence of initial cell spreading from integrin activation and traction. Nat Cell Biol 10:1062-1068. 